\title{
PARANAPIACABA: DINÂMICA ECONÔMICA EM FUNÇÃO DE SEUS EVENTOS
}

\author{
Aline Correia de Sousa Colantuono* \\ Natália Galindo Cestaro**
}

\begin{abstract}
Resumo
A Vila de Paranapiacaba guarda um patrimônio histórico e cultural desde sua ocupação territorial no Estado de São Paulo durante o desenvolvimento da cultura cafeeira. Com a aquisição da Vila pela prefeitura de Santo André em 2001, uma série de estratégias, como o Festival de Inverno de Paranapiacaba e o calendário de eventos, foi planejada para incentivar o turismo e a recuperação econômica da região. Tombada como patrimônio nas esferas municipal, estadual e federal, a Vila é candidata a patrimônio da humanidade pela UNESCO. Desde 2013, ela recebeu para restauro o investimento de $\mathrm{R} \$ 42$ milhões do Programa de Aceleração do Crescimento (PAC), o que pode potencializá-la a tornar-se um dos maiores polos turísticos do Estado de São Paulo. Diante desse cenário, o trabalho investiga, por meio de revisão bibliográfica, de dados da prefeitura e de entrevistas com os comerciantes e com o órgão público, a potencialização do turismo na região através de seus eventos e da diversificação econômica oriunda deles. Percebeu-se que é necessária a criação de uma identidade local, a partir da qual os moradores sintam-se parte integrante do patrimônio. Assim, a consolidação econômica de Paranapiacaba precisa pautar-se em uma inter-relação entre a comunidade e o poder público, a fim de que recursos sejam priorizados e capacidades empreendedoras sejam desenvolvidas. A diversificação do calendário de eventos representa um catalisador para a transformação comunitária, gerando resultados que potencializam a individualidade de seus sujeitos.
\end{abstract}

Palavras-chave: Paranapiacaba. Eventos. Turismo Cultural. Dinâmica Econômica.

\footnotetext{
* Economista pelo UNI-FACEF, mestre em Economia pela Universidade Estadual Paulista Júlio de Mesquita Filho, doutoranda em Desenvolvimento Econômico na Universidade Estadual de Campinas, professora da Faculdade de Tecnologia do Ipiranga e da Faculdade de Tecnologia de São Caetano do Sul.

E-mail: alinecsousa@yahoo.com.br

** Graduada em Gestão de Eventos pela Fatec Ipiranga, certificada em Turismo e Hospitalidade pelo Whatcom Community College (EUA), aluna do Community College Initiative Program do Departamento de Estado dos Estados Unidos, e instrutora de língua inglesa. E-mail: gc.natalia@hotmail.com
} 


\section{Introdução}

O turismo tem sido identificado como uma atividade produtiva moderna e de significativa participação nos setores econômicos das localidades onde está inserido, sendo sua absorção pela comunidade ligada aos fatores culturais, territoriais e econômicos de tais localidades. Tais fatores são utilizados de maneira côngrua para o desenvolvimento das atividades econômicas do espaço turístico, fazendo com que haja o consumo do espaço. Dentre as principais características para o seu desenvolvimento, o turismo apropria-se de eventos, paisagens, ocupação do espaço, condições ambientais etc.

Existe, portanto, uma relação muito forte entre eventos e turismo, o que reflete diretamente no desenvolvimento econômico de uma região [...] a promoção de eventos se funde à atividade turística, através de ações interligadas à economia do municípiosede. (COUTINHO; COUTINHO, 2007, p. 2).

Nesse sentido, os eventos, sendo uma realidade da atividade turística, atuam como multiplicadores de renda e movimentadores do capital local, podendo angariar uma gama de benefícios socioeconômicos à localidade onde estão inseridos. Dentre os impactos positivos da atividade turística, destaca-se o aumento da renda local, uma vez que os gastos despendidos no local representam a injeção de novos recursos na economia. Além disso, o aumento da atividade turística representa maiores investimentos na infraestrutura dos destinos que beneficiam a população local, além da geração de empregos (IGNARRA, 2007).

No caso de Paranapiacaba, os eventos que ali são promovidos estão intimamente ligados ao atrativo turístico da região, sendo parte do turismo cultural da região, que é uma estratégia da Prefeitura de Santo André para recuperação econômica local. Por turismo cultural, entende-se aquela modalidade de turismo fundamentado e instigado por algum aspecto da cultura humana, seja erudita ou de entretenimento. 
A Organização Mundial do Turismo apud Barreto (2002, p. 20) afirma que "[...] o turismo cultural seria caracterizado pela procura por estudos, cultura, artes cênicas, festivais, monumentos, sítios históricos ou arqueológicos, manifestações folclóricas ou peregrinações".

Dessa maneira, dado o panorama histórico do surgimento da Vila de Paranapiacaba durante o ciclo econômico do café no Estado de São Paulo, que será abordado no desenvolvimento do trabalho, a viabilização do turismo na região apropria-se dos espaços físicos na intenção de reproduzir ou criar memórias sobre a região, conectando-se diretamente com a preservação de seu patrimônio histórico, ao mesmo tempo em que os eventos culturais que ali acontecem promovem sua imagem e desenvolvimento econômico, trazendo relevância à cultura de Paranapiacaba.

Com o passar dos anos, a Vila de Paranapiacaba não apenas esteve suscetível às mudanças econômicas do Estado de São Paulo, mas também à ação do tempo e da intervenção humana desordenada que levou, em diversos momentos de sua história, à sua degradação quase completa. Por esse motivo, a organização territorial, cultural e econômica da Vila, após o período áureo da cultura cafeeira, esteve alheia às necessidades locais de seus moradores, o que fez com o que o seu desenvolvimento estivesse à mercê de fatores externos de seu território. Moretto Neto (2015) sugere que, não fosse a incorporação da Vila de Paranapiacaba à gestão do distrito de Santo André no ano de 2002, ela estaria destruída. Dados dessa pesquisa apontam que os desenvolvimentos de políticas públicas e de incentivo ao turismo pela prefeitura de Santo André permitiram que Paranapiacaba tivesse sua economia sustentada em grande parte pelo turismo. Tal fato é confirmado por dados da Prefeitura Municipal de Santo André (2007 apud STIGLIANO; CÉSAR, 2008, p. 9):

No ano de 2003, Paranapiacaba registrou a visita de 95.958 turistas, ao passo que, em 2006, a Vila foi visitada por 221.360 pessoas. Este incremento visível tem repercussões para a localidade, por 
exemplo, quando se observam os números de empreendimentos turísticos, que, em 2003, eram 58 estabelecimentos e, em 2005, já eram 75, entre meios de hospedagem, serviços de alimentos e bebidas, empresas de receptivo etc.

Diante desse contexto, neste artigo pretende-se compreender o dinamismo econômico ocasionado pelo Festival de Inverno e pelo calendário de eventos e sua relevância para a Vila de Paranapiacaba. Por sua vez, como objetivos específicos buscam-se: a) avaliar se os indicadores econômicos do Festival de Inverno angariam benefícios socioeconômicos para os moradores da Vila; b) qual a participação efetiva dos eventos no desenho do plano de turismo da Vila e, por fim, c) avaliar os efeitos dos eventos para a população de Paranapiacaba.

Para a execução do presente trabalho, foram utilizadas além da revisão teórica, a coleta de dados estatísticos sobre a Vila de Paranapiacaba, a aplicação de formulário com comerciantes locais e uma entrevista com o órgão público orientada como recurso de pesquisa, ambas realizadas no ano de 2015. Utilizou-se o método narrativo e de quadro resumo para a exposição dos dados das entrevistas via e-mail realizadas com o órgão público de Santo André e dos formulários respondidos por 15 comerciantes da Vila de Paranapiacaba.

O formulário quantitativo-descritivo estruturado foi entregue face a face aos comerciantes para serem preenchidos individualmente. Dos 15 entrevistados, cinco declararam não saber ler e pediram a leitura e o preenchimento dos formulários por parte das autoras. A reflexão dos dados apresentados pelas entrevistas e pelos formulários respondidos foi somada ao aprofundamento da revisão da bibliografia que aborda os aspectos econômicos do turismo e dos eventos em conjunto com a economia comportamental, a fim de compreender a relação exercida entre os agentes econômicos.

Sendo a história da Vila datada de meados do século XIX, tratou-se brevemente do ciclo econômico do cultivo do café no Estado de São Paulo, a fim de compreender o processo histórico da fundação da Vila de Paranapiacaba e 
sua influência no desenvolvimento de políticas de turismo posteriores. Para tal, dados históricos foram extraídos dos trabalhos de autores como Dr. Wilson Cano, Dra. Thaís Cruz, Dr. Luiz Ignarra, Dra. Beatriz Stigliano e Me. Marco Moretto Neto. Paralelamente, foram lidos e analisados os trabalhos apresentados em simpósios de turismo e publicados em periódicos científicos, além de documentos do acervo histórico da Prefeitura de Santo André para melhor compreensão do cenário atual de desenvolvimento da Vila de Paranapiacaba. A revisão teórica cobriu a leitura do livro de Margarita Barreto, a fim de que se compreendam e se construam relações entre o turismo cultural, o patrimônio histórico e os eventos.

Posteriormente, foram lidos relatórios da Prefeitura de Santo André em conjunto com formulários aplicados diretamente à população de Paranapiacaba, a fim de coletar uma amostragem dos indicadores econômicos e de turismo. Para a compreensão da relevância e da contribuição dos eventos para o plano turístico da Vila de Paranapiacaba, foi realizada uma entrevista com o diretor do Apoio Administrativo de Paranapiacaba e Parque Andreense da área da Administração Municipal, responsável pela gestão do patrimônio de Paranapiacaba, e com o Departamento de Turismo da Secretaria de Turismo e Cultura de Santo André.

Esta pesquisa se justifica uma vez que a Vila de Paranapiacaba tem, desde a sua aquisição por Santo André, recebido investimentos para fomentar o seu potencial turístico, onde eventos consolidados como o Festival de Inverno, que já teve sua $15^{\circ}$ edição, é parte contundente do plano de turismo e uma das principais ferramentas de promoção da atividade turística da Vila (MORETTO NETO, 2005).

Essa pesquisa foi realizada a partir da necessidade de despertar o olhar para o envolvimento comunitário e para a participação social em atividades de turismo que são pensadas como agregadoras econômicas. Em Paranapiacaba, essa realidade torna-se mais relevante, visto que, desde 2002, a Vila de Paranapiacaba é tombada pelo Instituto do Patrimônio Histórico e Artístico Nacional e, em 2013, mesmo período em 
que a UNESCO homologou sua candidatura à Patrimônio da Humanidade, recebeu $\mathrm{R} \$ 42$ milhões do Programa de Aceleração de Crescimento (PAC) para sua restauração, cujas obras, ainda em andamento, podem tornar a Vila um dos maiores polos turísticos do Estado de São Paulo (ROSATI, 2013). Nesse sentido, os aspectos naturais e patrimoniais tornam-se atrativos para o turismo e, consequentemente, para os eventos, que atuam como promotores do destino, multiplicadores de renda e movimentadores do capital local, podendo tornar-se angariadores de uma gama de benefícios socioeconômicos para os moradores da Vila de Paranapiacaba.

Para caracterizar o dinamismo econômico, abordase brevemente a estrutura econômica do turismo levando em consideração o ser emocional como agente econômico, a experiência do consumidor na consolidação dos eventos, e as relações entre público, morador e Estado no desenho das dinâmicas econômicas da Vila. Para tanto, além da introdução e das considerações finais, este trabalho está dividido em três seções.

A primeira seção explora as relações econômicas de turismo em eventos, tendo como base teórica, além da microeconomia, o estudo elementar da economia comportamental, o qual considera que o indivíduo age além da racionalidade ao adquirir um produto turístico e/ ou de entretenimento. Essas teorias foram utilizadas para compreender a influência dos eventos para a diversidade econômica de Paranapiacaba.

A segunda seção aborda as características dos festivais, levando em consideração a experiência do consumidor, a intangibilidade do evento cultural enquanto produto turístico, e a relação do público com a localidade para o desenvolvimento de um calendário de eventos que lide com a sazonalidade econômica ocasionada pelos eventos.

Por fim, na terceira seção apresenta-se o contexto histórico econômico no qual Paranapiacaba se desenvolveu, com ênfase para a cultura cafeeira paulista no cenário econômico, o surgimento das atividades de turismo e eventos 
na Vila de Paranapiacaba, a fim de compreender a sua importância econômica para seus moradores, e a integração dos eventos no plano turístico, compreendendo como agem como transformador social a partir do envolvimento comunitário, da valorização da produção local e da ressignificação cultural da Vila de Paranapiacaba.

\section{Relações econômicas de turismo e eventos}

Economia comportamental e sua influência na economia do turismo

A economia comportamental é uma área de estudo que leva em consideração fatores sociais e emocionais, a fim de explicar decisões financeiras tomadas por seus agentes econômicos na aquisição de bens materiais ou imateriais. Ela reunifica a psicologia à economia de maneira a predizer comportamentos econômicos e desenhar suas políticas. Afinal, “[...] um homem não é um imutável 'pacote de desejos', mas tem 'propensões e hábitos que buscam expressão em atividades determinadas', uma das quais seria o comportamento econômico" (COSTA, 2009, p. 13). Uma vez que, de acordo, com a economia comportamental, o gasto do indivíduo, em qualquer natureza e instância, é pautado também por seu envolvimento emocional, por certo se pode caracterizar que os efeitos de uma atração turística são diferenciados para cada um de seus espectadores.

No planejamento e desenvolvimento da atividade turística, os indicadores econômicos do turismo e eventos correlacionam-se com fundamentos microeconômicos - oferta e demanda. Por oferta, compreende-se aquilo que é ofertado a um mercado para satisfazer um desejo e necessidade do consumidor a um determinado preço em um determinado momento. Em suas variáveis, constam o custo de produção, a concorrência, a tecnologia e o preço. Por demanda, compreende-se o indivíduo ou coletivo disposto a consumir o produto turístico a fim de "suprir suas necessidades de descanso, 
recreação, entretenimento e cultura” (MINISTÉRIO DO TURISMO, 2010). Os fatores que interferem na demanda são: renda, tempo de lazer, tecnologia e mobilidade (LAGE; MILONE, 1998).

Dessa maneira, as variáveis propostas por Vieira (2004), para simplificar essa relação, estão expostas na função (1), como segue:

$\mathrm{V}(\mathrm{n}) \mathrm{i}(\mathbf{1})$, onde:

$\mathrm{V}=$ valor $\quad \mathrm{n}=$ quantidade $\quad \mathrm{i}=\mathrm{bem}$

Essa função agrupa tanto o valor (v) que o indivíduo atribui ao consumir um produto ou serviço como também uma quantidade (n) de um bem (i). Nesse sentido, o valor positivo ou negativo atribuído a um serviço ou bem tal qual o da atração turística é diretamente exponencial a sua oferta.

Por sua vez, tendo o Ministério do Turismo (2010, p. 26) caracterizado o produto turístico, e por presunção os eventos, como:

- Intangível: por ser um bem de consumo abstrato e intangível, o turista não pode tocar ou armazenar o produto, bem como transportá-lo em uma mala, ele vive a experiência e a guarda na memória.

- Limitado: a produção de serviços é limitada à determinada quantidade, em um determinado tempo e espaço.

- Sazonal: concentra-se em algumas épocas e locais específicos, o que acaba por induzir a criação de produtos diferenciados para serem vendidos ao longo de todo o ano.

- Sistêmico: todos os produtos e serviços de uma atração turística estão interligados. Como o turista necessita de produtos e serviços variados, a ausência de um deles poderá inviabilizar ou dificultar a experiência vivida pelo turista. 
- Variável em seu valor percebido: a avaliação feita pelo turista será de acordo com a qualidade da experiência vivida por ele, que pode ser diferente da experiência de outros na mesma viagem.

De acordo com as características acima atribuídas, poder-se-ia dizer que as variáveis convencionais preço e quantidade apresentadas na curva da demanda seriam substituídas por novos agentes, verticalizando a curva e o ponto de equilíbrio, conforme se observa no Gráfico 1.

Gráfico 1 - Sugestão da dinâmica de oferta e demanda na realização do evento cultural

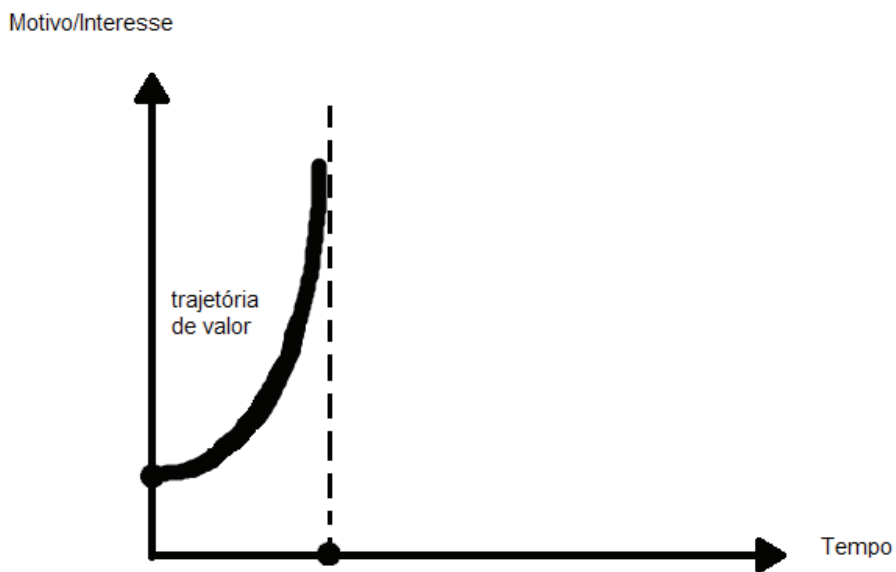

Fonte: Elaborado pelas autoras com base nos conceitos da economia comportamental associados à microeconomia, a partir de Vieira (2004, p. 19).

O tempo, aqui definido como a realização do evento, permanece estável, pois é fixo e determinado, sendo de sua característica ser único em cada um de seus acontecimentos. Entretanto, o interesse e a motivação da participação do consumidor irão aumentar na medida em que mais valores forem percebidos e associados ao evento. Esse incremento de valores aumenta à medida que se aproximam da motivação inicial, atingindo, assim, um ponto de equilíbrio vertical se o evento corresponder às expectativas. 
O que se pode compreender é que a demanda turística e

cultural de eventos se vincula a uma série de fatores que estão relacionados às preferências e às motivações dos visitantes/ espectadores. Cabe aos organizadores de eventos, à gestão das atividades de turismo e aos empresários, compreender o comportamento daqueles que compõem o fluxo de turismo e eventos, a fim de que ajustem a oferta de produtos e serviços que potencializem a experiência do indivíduo. Os conhecimentos superficialmente apresentados podem ser usados para explicar determinadas dinâmicas na realização de evento (por exemplo: fluxo de público, tempo de permanência, gasto por pessoa etc.) e quais estratégias mostram-se eficazes no cumprimento de determinados objetivos. Oferece uma nova ótica para olhar a dinâmica econômica, tendo como base o seu agente mais eficaz: o consumidor.

Influência dos eventos e turismo na diversidade econômica de Paranapiacaba

A Vila de Paranapiacaba teve sua consolidação enquanto polo urbano no período econômico do café, tendo, em sua despretensiosa localização geográfica, fatores que impulsionaram seu desenvolvimento. É necessário que se compreenda que Paranapiacaba sofreu um processo de degradação, cuja revitalização foi possível com a sua aquisição por Santo André e com o investimento em políticas para transformá-la em polo turístico a partir de 2001. Assim, frente a uma crise econômica, a Prefeitura de Santo André identificou e apropriou-se do potencial turístico da Vila de Paranapiacaba para dinamizar a economia e preservar seus recursos culturais.

Entende-se que “[...] o turismo cultural [e por extensão os eventos] possa ser um produto realmente autêntico e trazer benefícios não somente econômicos como também socioculturais aos protagonistas" (BARRETO, 2002, p. 30, Grifo das autoras). No caso de Paranapiacaba, os eventos tal qual o Festival de Inverno e o turismo constituem uma série de 
ações para a promoção e o empoderamento local. Assim, tratase de uma via de mão dupla: além de incentivar a economia, também enriquece culturalmente a localidade. Segundo Caetano apud Oliveira (2005, p. 1, Grifo das autoras ): "O lado cultural é um pretexto, um atrativo. $\mathrm{O}$ mais importante é o que o evento [Festival de Inverno] injeta de recursos no comércio local. $\mathrm{O}$ aspecto principal certamente é a geração de renda".

A Diretoria de Turismo de Paranapiacaba, em entrevista concedida às pesquisadoras, afirma que:

$\mathrm{Na}$ verdade, o Festival de Inverno não é uma ferramenta isolada, mas faz parte um conjunto de ações que contribuem para mudar a imagem externa da Vila de Paranapiacaba, aumentar e qualificar o perfil de visitantes, estimular o envolvimento dos moradores no processo de desenvolvimento, gerar divulgação e promoção turística, estimular a requalificação e criação de infraestrutura turística e voltar atenção e buscar recursos para a restauração do patrimônio construído e das identidades locais.

Ainda que não se tenha pesquisado com afinco a motivação do público de Paranapiacaba, Barreto (2002, p. 20) afirma que: "[...] o turismo de tipo diversionário e recreacionista é ainda praticado pela classe trabalhadora. Procuram no turismo uma válvula de escape e a recuperação das forças físicas e mentais". Com esse entendimento, pode-se afirmar que o turista e, por consequência o público dos eventos de Paranapiacaba, cujo perfil será estudado adiante, contextualizam o conceito hedônico da economia comportamental, no qual produtos são adquiridos mais pelo envolvimento afetivo do que por sua funcionalidade. Assim, o nível de satisfação é correlacionado com as experiências positivas encontradas ao longo da compra ou, nesse caso, vivência do produto.

Dessa maneira, a eficácia da implantação de um calendário de eventos e de todas as estruturas que envolvem a sua realização e que atue duplamente na satisfação do público 
e no angariamento de benefícios para a população leva em consideração motivação, experiências anteriores e equilíbrio emocional dos visitantes. Assim, as relações econômicas benéficas, que surgem dessa rede, podem ser entendidas como aumento da renda, melhoria da infraestrutura e ampliação de investimentos da localidade de destino, onde, nesse sentido, o calendário de eventos atue como ferramenta estratégica do turismo cultural para o desenvolvimento econômico local. No caso de Paranapiacaba, com a promoção do Festival de Inverno e a consolidação de um calendário de eventos ativo, o ticket médio que é deixado pelo público e que hoje aumenta em cerca de apenas $20 \%$ a renda dos comerciantes locais, poderia ser elevado para $\mathrm{R} \$ 70,00$ por pessoa, como é o plano da Diretoria de Apoio Administrativo de Paranapiacaba, o que acarretaria em uma arrecadação anual de $\mathrm{R} \$ 15.400 .000^{1}$ oriundas apenas do turismo cultural.

\section{Festivais de inverno: experiência do consumo e Sszonalidade}

\section{Festival: vivência da infraestrutura de lazer}

O Festival de Inverno de Paranapiacaba é o maior evento da Vila que surge como uma estratégia de desenvolvimento, promoção e recuperação do local. O público dos festivais, eventos atrativos de massa ${ }^{2}$, considerado classe $\mathrm{C}$, prioriza a viagem de baixo custo, o transporte rodoviário, o pagamento a vista e a hospedagem em casa de parentes/amigos ou em pousadas.

De acordo com o Ministério do Turismo ([s. d.]), optam por excursões de curta duração e viagens "bate e volta", aos finais de semana e, muitas vezes, dentro de seus Estados de origem. O principal motivo de viajarem é passeio/descanso e as atrações no destino são: jogos de futebol, circuitos histórico-cultural, shows, viagens de formatura, festivais, festas, ecoturismo e religião. Grande parte de suas viagens são
1 A visitação geral da Vila, logo seu fluxo turístico anual, foi de cerca 200 mil visitantes em 2013, segundo Moretto Neto (2015). Em 2015, conforme o Anuário de Santo André (2016), a Vila de Paranapiacaba atraiu 254.570 visitantes. Então, acredita-se que a arrecadação da Vila com o turismo cultural possa ser ainda maior.

2 Turismo de massa pode referir-se ao volume de turistas ou aos gastos despendidos, sendo o turismo de massa mais coletivo e econômico (IGNARRA, 2007). 
de pequena duração (1-3 dias) e pequena distância (até 300 $\mathrm{km})$ com gasto médio de $\mathrm{R} \$ 118,00$ totais em sua viagem.

Em Paranapiacaba, turistas de um dia e visitantes representam a parcela mais significativa dos consumidores, com perfil turístico qualificado como classe $\mathrm{B}$ e $\mathrm{C}$, familiar e na faixa etária entre 25 e 40 anos. $\mathrm{Na}$ realidade desse público de eventos como o Festival de Inverno, evidencia-se a característica do acontecimento enquanto produto. A eficácia dos eventos enquanto entretenimento reside na ideia do encantamento, necessária a completa imersão do sujeito, a fim de que este perca a noção do que o circunda e, nesse sentido, fuja e alivie-se de seu cotidiano.

O consumo é visto como um estado subjetivo de consciência acompanhado por significados simbólicos diversos. À racionalidade são incorporadas variáveis anteriormente negligenciadas que permitem reconhecer claramente o papel das emoções no comportamento, passando o consumidor a ser compreendido mais como uma criatura de sensações e emoções do que de ação, dando origem ao consumo simbólico, necessidades de prazer e diversão que vão além do ato da compra, do uso do produto e da escolha da marca. (ADDIS; HOLBROOK, 2001 apud SOUZA JÚNIOR, 2013, p. 22).

Os eventos proporcionam ao visitante a vivência do local, através da experimentação e integração em sua cultura. Diferentemente dos museus tradicionais ou exposições artísticas, a participação em um evento, tal como um concerto ou um festival tira a passividade do público e o torna ativo, capaz não apenas de apreciar, mas envolver-se com a atração e com o local. Assim, "[...] ao participar de eventos, o ser humano enriquece a sua vida emocional e social, educa seus sentidos, prioriza o seu olhar, adquire uma nova visão de mundo, absorve novos conhecimentos e vive novas experiências" (COUTINHO; COUTINHO, 2007, p. 2).

As inter-relações do indivíduo com o espaço e com o outro vão constituindo as relações de experiência e a percepção dos elementos emocionais que surgem do consumo. 
Expectativa, espaço de vivência, interatividade, o sujeito centrado em si e a temporalidade atreladas ao reflexo do diálogo ocasionam ao turista o contexto de descoberta de sua própria experimentação (SOUZA JÚNIOR, 2013). Assim, ainda que se oferte o mesmo produto, cada consumidor distingue as características que para si são destacadas; logo, cada experiência que é ligada ao individual é interpretada de uma maneira diferente.

Nesse sentido, a aquisição, a percepção e a avaliação do produto turístico que é intangível por natureza precisam pautar-se na criação de laços que permitam o envolvimento econômico dos seus consumidores. Como explica a Economia Comportamental, a emoção é uma variável comportamental que influencia a decisão de compra (PAIVA, 2013).

Dessa maneira, é certo dizer que o fenômeno da experiência tem influenciado as relações tradicionais de compra e venda. As empresas do setor turístico precisam considerar o ser como indivíduo multifacetado, a fim de agregar valor a seu produto ou serviço para que ele se destaque no processo de aquisição. Para eventos delineados como atrativos turísticos, tais características devem ser pensadas desde o seu planejamento, no qual todas as variáveis (local de realização, época do ano, distância do público alvo, preço etc.) influenciam as relações que o público construirá com a localidade. O consumo do turismo torna-se, então, uma conjugação de experiências que não se fragmentam.

A forma como o mesmo percebe o destino turístico, interage e gera novas percepções envolve desde o momento que o local é escolhido, passando pelo período em que é vivenciado, e culminando no registro das lembranças, que são repassadas a outros sujeitos por meio da comunicação. (XU, 20093 apud SOUZA JUNIOR, 2013, p. 10).

3 Ver Perceptions of tourism products (XU, 2009).

Paranapiacaba pode ser considerada um local de grande apelo turístico. Como comumente é citado, seu clima peculiar, sua arquitetura diferenciada, sua localização e sua 
história tecnológica são alguns dos fatores que lhe agregam valor. A particularidade do clima úmido, com densa neblina e atmosfera inglesa potencializados durante o inverno em julho, fomentaram a proposta do Festival de Inverno como dinamizador econômico da região. $\mathrm{O}$ evento tem potencializado a economia da Vila, movimentando todos os seus setores. Por esse motivo, não apenas na realização do Festival mas também nos demais eventos, é necessário que haja diálogo entre os setores, a fim de que se unifique a experiência de seus visitantes. Quanto mais uniforme a experiência do consumidor, e próxima de suas expectativas, maior o potencial de investimento e valor econômico despendido pelo visitante.

\section{Eventos em Paranapiacaba: festival de inverno em números e experiências de seus comerciantes}

\section{História e economia de Paranapiacaba}

Paranapiacaba, o lugar de onde se vê o mar, assim chamada pelos índios tupis da região, é reflexo do desenvolvimento econômico do país e um patrimônio que guarda a história da ocupação territorial do Estado de São Paulo. Sua história pode ser traçada em paralelo com o auge da indústria cafeeira em São Paulo. Primeiramente, a agricultura

4 São Paulo Railway (SPR) foi uma empresa contratada para realizar a obra e gerenciar o transporte por 90 anos em Paranapiacaba (PREFEITURA DE SANTO ANDRÉ, 2014b, p. 32). do café; depois, a mobilidade ocasionada pela construção da ferrovia pela companhia inglesa São Paulo Railway ${ }^{4}$ (SPR) e, por fim, o legado de construções, paisagens e atividades deixadas por tal desenvolvimento.

A economia cafeeira paulista em São Paulo foi a única célula exportadora capaz de gerar uma importante e precoce urbanização tanto no sentido Capital (São Paulo) - litoral (Porto de Santos) quanto na direção do interior, onde as bases técnicas e econômicas do café exigiram sólida base urbana, gerando uma formidável rede de cidades de médio e pequeno porte. (CANO, 1988, p. 70).

É nesse contexto, de uma cultura cafeeira em constante expansão e exportação, ocasionada pela fertilidade das terras, 
alta produtividade física da força de trabalho e desenvolvimento urbano e de tecnologias como o complexo ferroviário, que a Vila de Paranapiacaba começa a ganhar destaque e desenvolver-se economicamente sob o pilar da mobilidade ocasionada pela construção da ferrovia pela companhia inglesa SPR.

Dentre os principais componentes do complexo cafeeiro paulista, Paranapiacaba inter-relaciona-se com os que são a seguir destacados por Cano (2007, p. 29):

- A atividade produtora do café [e a disponibilidade de terras].

- A implantação e o desenvolvimento do sistema ferroviário paulista.

- A atividade do comércio de exportação e de importação.

- O desenvolvimento de atividades criadoras de infraestrutura-portos e armazéns, transportes e comunicações [...].

- O movimento imigratório.

No tocante à atividade produtora do café e à disponibilidade das terras, devido à rápida exaustão do solo, o cultivo do café foi expandindo-se para regiões afastadas do litoral, penetrando o interior do Oeste Paulista e distanciandose das regiões portuárias onde era escoado para exportação. Em sua localização geográfica, Paranapiacaba localiza-se em um ponto estratégico ante ao deslocamento do interior para a descida da Serra do Mar através do sistema ferroviário, o que contribuiu para que se tornasse um ponto de descanso e, através de acampamentos para os trabalhadores, ali se desenvolvessem os primórdios da Vila.

A produção do café é uma das grandes responsáveis pelo surgimento do complexo ferroviário paulista, pois propiciou o desenvolvimento de infraestruturas as quais permitiram ao Estado de São Paulo posicionar-se como polo econômico e destacar-se durante os movimentos migratórios do século seguinte (CRUZ, 2007). As ferrovias representavam o destaque tecnológico da região e a supremacia da lucratividade com o produto, pois baixavam os custos da produção. 
À medida que a fronteira agrícola do café mais se distanciasse, em direção ao interior, surgiria um freio natural a essa acumulação representado pelos altos custos de transporte do produto, entre as zonas produtoras e o porto de embarque. A superação desse obstáculo se daria pela implantação do sistema ferroviário. (CANO, 2007, p. 42).

Assim, as ferrovias como aliadas à produção cafeeira com o intuito de tornar seu transporte mais barato e seguro, são também inter-relacionadas com as atividades do comércio de importação e exportação. Para Paranapiacaba, essa dúbia relação acontece, pois a cidade surge por conta da construção do São Paulo Railway [SPR], desenhada para conectar Jundiaí ao escoamento do produto até o porto de Santos para sua exportação. Com um investimento de capital inglês de 6,7 milhões de libras em 1867, a construção da SPR foi uma concessão dada a Irineu Evangelista de Sousa, o Barão de Mauá, que se desenvolveu como acionista da São Paulo Railway Company, cujo primeiro projeto para a ferrovia marca o início da história de Paranapiacaba.

O vínculo entre o café e a ferrovia se dá porque ambos desempenham papel fundamental para essa ocupação territorial [...] promovendo também um processo de urbanização na cidade de São Paulo e nas cidades ao longo da linha da SPR [São Paulo Railway] que também cresceram e se desenvolveram acompanhando esse surto de crescimento. (CRUZ, 2007, p. 16).

A construção ferroviária causa uma valorização da área a qual atende, criando uma espécie de povoado-estação, dada a movimentação comercial que passa a se desenvolver na região. Assim, é com a construção da ferrovia que Paranapiacaba, que primordialmente servia de acampamento para operários, tornou-se a Estação Alto da Serra em 1867, o último ponto antes da descida da serra e o local de manutenção dos trens e do sistema ferroviário (PREFEITURA DE SANTO ANDRÉ, 2013). 
Após o tempo áureo de seu desenvolvimento econômico, a partir da crise mundial de 1929, com os preços do café caindo e empurrando São Paulo para a diversificação de plantio e para a industrialização, é certo afirmar que Paranapiacaba, em sua condição de "ponto de passagem" (ALLIS, 2002, p. 42), não foi incorporada a essa mudança de cenário, o que levou ao seu quase esquecimento nas décadas seguintes. Visto que em 1946 terminou o período de concessão da ferrovia à SPR e todo o seu patrimônio foi incorporado ao Governo Federal, nesse período aconteceram os primeiros passos para a decadência de Paranapiacaba, a partir da utilização cada vez menos frequente da ferrovia. Com a desvalorização do café, o início da industrialização e o desgoverno inglês, a Vila ficou suscetível às políticas governamentais, que apesar de a elevarem à condição de patrimônio histórico, não foram suficientes para manter sua subsistência.

A Vila de Paranapiacaba viu, então, a sua degradação abarcar o legado de construções, as paisagens e as atividades deixadas pelos tempos áureos de seu desenvolvimento (PREFEITURA DE SANTO ANDRÉ, 2013).

Desse modo, sugere-se que a mudança do paradigma econômico acabou levando Paranapiacaba, décadas seguintes, a um processo de degradação (CRUZ, 2013). Com isso, muitas pessoas saíram da Vila em busca de oportunidades e ela foi ocupada por quem não tinha vínculo com o local ou com sua história. Foi após o anexo do distrito de Paranapiacaba à Prefeitura de Santo André, em 2002, que novas políticas passaram a ser desenvolvidas para a restauração dos aspectos históricos, estruturais, ambientais e culturais da região.

\section{O estímulo econômico ocasionado pelos eventos na vila}

O Festival de Inverno de Paranapiacaba (FIP) acontece desde 2001 após a Vila ser adquirida por Santo André, quando houve a implantação de uma gestão local, a Subprefeitura de Paranapiacaba e Parque Andreense 5 . O FIP foi uma ação desencadeadora do turismo e de revitalização da identidade da

5 Em 2009, foi reorganizada a fim de que se tornasse a Secretaria de Gestão dos Recursos Naturais de Paranapiacaba e Parque Andreense, atual unidade administrativa local. 
Vila, por meio do qual o poder público, empresas privadas, o terceiro setor e a comunidade local atuam juntos na realização do evento (MORETTO NETO, 2005). Conta com uma série de atividades culturais que acontecem no mês de julho durante dois finais de semana completos. $\mathrm{O}$ clima e a arquitetura histórica são atributos que intensificam a atmosfera do local e geram uma série imagens no imaginário coletivo, contribuindo para o sucesso de tais atividades.

A primeira edição do Festival de Inverno de Paranapiacaba aconteceu em 2001, com um custo aproximado de $\mathrm{R} \$ 60$ mil e uma programação plural de exposições artísticas, shows e oficinas. A iniciativa, além de integrar ações para promover o turismo na região teve por objetivo oferecer aos $17 \%$ da população local que estava desempregada, uma alternativa de protagonismo e segurança de renda (NEVES, 2001).

Para a 2a edição, desde o seu planejamento, consolidouse a proposta da expansão da utilização dos espaços públicos e o início de discussões e reflexões sobre a Vila. $\mathrm{O}$ orçamento para a realização quintuplicou e foi previsto investimento de $\mathrm{R} \$ 300$ mil, com $\mathrm{R} \$ 150$ mil disponibilizados pela Prefeitura de Santo André. Já nessa edição, o Festival consolidava-se como "a espinha dorsal de toda a programação anual" (MORETTO NETO apud GUTIERRE, 2002).

Em 2003, houve um aumento das atividades ao ar livre e a exposição cultural da produção artística de diversas cidades da região do ABC Paulista. Com orçamento de R\$ 100 mil, 70\% da Prefeitura foram investidos em suprimento de energia, banheiros públicos, palco, som e atrações. $\mathrm{O}$ restante do investimento veio de patrocinadores como PqU - Petroquímica, Petrobras e Caixa Econômica Federal (SOARES, 2003).

A consolidação da imagem de Paranapiacaba e, consequentemente, do Festival que em 2005 atingiu a sua $5^{\text {a }}$ edição, aconteceu ao passo que "[...] em 2004, foram 8 mil pessoas que estiveram em Paranapiacaba no fim de semana inaugural do festival. Neste ano, foram 23 mil, que deixaram 
no comércio cerca de $\mathrm{R} \$ 55$ mil - no ano passado, no mesmo período, o faturamento foi de R $\$ 41$ mil”(OLIVEIRA, 2005).

Isso reafirma que a realização do Festival representou uma alternativa sólida de complemento de renda para os moradores, que geraram um movimento cerca de $500 \%$ se comparado ao final de semana regular, superlotando as 13 pousadas locais e findando os estoques ainda no primeiro final de semana do evento. A realização de cerca das 120 atrações custou, aproximadamente, $\mathrm{R} \$ 1$ milhão, cinco vezes mais do que a primeira edição, sendo $\mathrm{R} \$ 300$ mil patrocinados por empresas como Petrobras, Caixa Econômica Federal e Banco do Brasil, Vigorito, Saúde ABC, cerca de R $\$ 650$ mil aplicados pela Prefeitura de Santo André e o restante por empreendedores locais (OLIVEIRA, 2005).

A $6^{a}$ edição do FIP foi uma das mais peculiares e ofereceu uma densa programação paralela, como a Feira de Vinil e a exibição de filmes ao ar livre. Para tal edição, a apresentação de blues e jazz foi a temática principal que atraiu cerca de 30 mil visitantes (NEVES, 2006).

Em 2009, as principais atrações foram Oswaldo Montenegro, Luiza Possi, Dorival Caymmi e Ná Ozzetti. Nesse mesmo ano, os ingressos foram trocados por doações de roupas e cobertores a serem doados para a Campanha do Agasalho (JORNAL DA ORLA, 2009). A 10a edição do Festival contou com nomes reconhecidos e consagrados da música popular brasileira, como Zeca Baleiro, Maria Rita, Léo Maia, Zélia Duncan e Ana Cañas (CATRACA LIVRE, 2010). Artistas como tais autopromovem o evento, pois devido à sua consolidação no ramo, direcionam cada qual seu público sólido para o evento.

Em 2015, a programação do FIP foi mais enxuta por conta de sua realização em conjunto com as obras do investimento do Programa de Aceleração do Crescimento (PAC) que prevê o restauro de 242 obras da Vila. O evento contou com a utilização de recursos do Fundo de Gestão do Patrimônio da Vila e recebeu apoio financeiro do SESC - SP, da 
6 Os nomes foram ocultados para preservar a identidade das fontes. rádio Eldorado FM e do Instituto ACQUA (PREFEITURA DE SANTO ANDRÉ, 2015).

Do ponto de vista de moradores e comerciantes entrevistados, por meio dos dados recolhidos através de formulários e resumidos em um quadro que pode ser observado adiante, verifica-se uma percepção distinta sobre o Festival de Inverno de Paranapiacaba e a promoção de eventos na Vila. Ainda que esteja consolidado, alguns moradores acreditam que as últimas edições não refletem o tempo áureo do Festival de Inverno. $\mathrm{O}$ evento que já apresentou diversos artistas renomados em edições anteriores, há tempos não traz o que D.F. ${ }^{6}$ chama de "nome de peso". Nascida e criada na Vila e dona de um estabelecimento de artesanato, D.F diz que o "espírito" do Festival está perdendo-se. Em formulário respondido, ela avalia a promoção do Festival como péssima, pois acredita que falta incentivo financeiro para a sua realização, com o nome de patrocinadores de "peso".

Quando questionada sobre a possibilidade da melhoria do fluxo turístico para a edição de 2016 por conta das obras de restauro, assim como outros comerciantes entrevistados, a pesquisada ainda se mostra relutante sobre os reais benefícios para a população. D.F. disse que ainda não viu aplicabilidade nas residências e na qualidade de vida dos moradores com o restauro. Outro respondente disse que os investimentos ainda não são notáveis. A responsável pelo projeto social da Vila, "Infinito Olhar", também acredita que os restauros não terão impacto nos eventos.

Analogamente, dos 15 respondentes do formulário apresentado na pesquisa de campo e sintetizados no Quadro 1 , nove manifestam-se incrédulos quanto ao investimento do PAC para revitalização da Vila de Paranapiacaba. Esses indicadores demonstram que as políticas de preservação não são neutras, mas reflexo da ideologia de quem faz as leis (BARRETO, 2002).

Em contrapartida, em entrevistas com a gestão pública de Paranapiacaba e resumidas no Quadro 2, notase a que o restauro dos imóveis acarretará no aumento da 
infraestrutura, pois muitos dos imóveis estão abandonados,

e em maior desenvolvimento do empreendedorismo local, com a qualificação positiva e aumento dos serviços turísticos. Como o restauro é parte da candidatura de Paranapiacaba à UNESCO, as obras projetarão a imagem da Vila e aumento de sua publicidade. Nesse sentido, a conservação deve implicar a integração do patrimônio ao dinamismo cultural em que se encontra.

Isso vai de encontro com a opinião de alguns moradores que afirmam que é necessária a maior divulgação dos eventos promovidos, sentimento unânime entre os entrevistados. S.A. diz que muitos dos empreendedores locais são "pegos de surpresa” com a realização dos eventos no local. Isso reflete também na educação cultural dos moradores que, em sua maioria, quando participam, o fazem como prestadores de serviços e não como espectadores do evento.

Os entrevistados também comentaram que é preciso maior promoção dos demais eventos que acontecem na Vila de Paranapiacaba. Ainda que o Festival de Inverno atraia um alto fluxo de público, e haja um diversificado calendário de eventos em Paranapiacaba que já está consolidado e com clara segmentação do público, como a Convenção de Bruxas e Magos que acontece em maio e está em sua $13^{\mathrm{a}}$ edição, a Festa do Padroeiro Bom Jesus de Paranapiacaba em sua 127a edição acontecendo tradicionalmente em agosto e o Encontro de Ferreomodelismo nos meses de novembro e está em sua 9a edição, diversos outros eventos que acontecem na cidade não são promovidos como a mesma efetividade e, por vezes, não chegam ao conhecimento dos moradores e comerciantes, conforme afirmam alguns relatos.

Nos quadros 1 e 2 a seguir, encontra-se o resumo das repostas obtidas com os formulários entregues à população de Paranapiacaba, bem como a síntese da entrevista realizada junto à Administração Geral de Paranapiacaba e à Secretaria de Cultura e Turismo de Santo André.

Os dados mostram que o percentual de visitação da Vila aumentou $655 \%$, conforme visto nas tabelas 1 e 2 a seguir, 
nos últimos dez anos, crédito que pode ser dado à série de atividades que ali começaram a ser desenvolvidas, em especial o Festival de Inverno.

\section{Quadro 1 - Síntese das Respostas de Formulário aplicado à População de Comerciantes de Paranapiacaba}

\begin{tabular}{|c|c|}
\hline \multicolumn{2}{|c|}{ Total de entrevistados: 15} \\
\hline $\begin{array}{l}\text { Perfil dos } \\
\text { Entrevistados }\end{array}$ & $\begin{array}{l}\text { - Apenas } 26 \% \text { são naturais de Paranapiacaba. } \\
\text { - Locais de origem: São Paulo capital, Minas Gerais, Pernambuco, Santo André e São } \\
\text { Bernardo do Campo. } \\
\text { - Motivo da mudança: busca por tranquilidade, mudança de hábito, trabalho na ferrovia. } \\
\text { - Todos os entrevistados trabalham no Setor Terciário: } 40 \% \text { no comércio, } 40 \% \text { na } \\
\text { prestação de serviços, } 20 \% \text { na administração pública. } \\
\text { - } 80 \% \text { trabalham na própria Vila de Paranapiacaba. } \\
\text { - } 73 \% \text { têm renda familiar mensal de } 0-2 \text { salários mínimos. }\end{array}$ \\
\hline $\begin{array}{l}\text { Atividade } \\
\text { Turística }\end{array}$ & $\begin{array}{l}\text { - Dez dos } 15 \text { entrevistados avaliam a atividade turística da Vila como Boa ou Ótima, por } \\
\text { ocasionar movimento econômico, mas aponta a necessidade de melhorias e de maior } \\
\text { investimento. } \\
\text { - Respondentes que avaliam como Insatisfeitos apontam despreparo dos empreendedores } \\
\text { locais. } \\
\text { - Mais da metade dos respondentes sugerem melhorias no transporte de acesso à Vila e } \\
\text { na infraestrutura de acomodação, alimentação e entretenimento para atrair mais turistas. }\end{array}$ \\
\hline Eventos & $\begin{array}{l}\text { - Promoção: A maioria considera Boa a promoção dos eventos. Há sugestão de mais } \\
\text { atraçôes para as crianças. Dos insatisfeitos, há sugestão de uso em outros meios além da } \\
\text { internet para divulgação e maior incentivo financeiro. } \\
\text { - É unânime entre os entrevistados a sugestão de maior divulgação dos eventos } \\
\text { promovidos na Vila como estratégia para atrair mais turistas. } \\
\text { - Participação: Apenas três respondentes disseram participar como espectadores. Os } \\
\text { demais afirmaram participar como prestadores de serviços. Entrevistados afirmaram } \\
\text { não saber da realização ou não ter conhecimento da data dos eventos. }\end{array}$ \\
\hline $\begin{array}{l}\text { Dinamismo } \\
\text { Econômico }\end{array}$ & $\begin{array}{l}\text { - Dez dos } 15 \text { entrevistados afirmaram se beneficiar economicamente da atividade turística } \\
\text { e dos eventos na Vila. Razões apontadas foram: comércio, venda de souvenir e maior } \\
\text { fluxo no final de semana. Entrevistada disse não lucrar no seu ramo de artesanato. } \\
\text { - Dez dos } 15 \text { entrevistados disseram aumentar em até } 20 \% \text { sua renda mensal com a } \\
\text { prestação de serviços nos eventos. } \\
\text { - } 73 \% \text { acreditam que os eventos contribuem para a ocupação dos estabelecimentos de } \\
\text { acomodação e alimentícios. } \\
\text { - Entrevistados apontam a necessidade de melhorar a estrutura de tais estabelecimentos. } \\
\text { - As opiniões dividem-se quando os entrevistados são questionados se os outros eventos } \\
\text { promovidos na Vila (além do Festival de Inverno) contribuem para o aumento do fluxo } \\
\text { nos estabelecimentos de acomodação e alimentícios. }\end{array}$ \\
\hline
\end{tabular}




\begin{tabular}{|c|c|}
\hline $\begin{array}{l}\text { Efeito dos } \\
\text { Eventos para a } \\
\text { população }\end{array}$ & $\begin{array}{l}\text { - As duas principais vantagens apontadas de eventos ocorrendo na Vila foram: oferta } \\
\text { de mais opções de entretenimento para a população local e ganho de visibilidade e } \\
\text { atratividade para promoção de outros eventos na cidade. } \\
\text { - Alguns entrevistados apontaram aumento da renda mensal e diversificação econômica } \\
\text { da cidade como vantagens dos eventos. } \\
\text { - } 73 \% \text { dos entrevistados não veem desvantagem em ter eventos acontecendo na Vila. } \\
\text { - } 50 \% \text { acreditam que a realização do Festival de Inverno promove melhoria na diversidade } \\
\text { econômica e no fluxo turístico. Entretanto, acreditam que o cuidado ambiental e a } \\
\text { infraestrutura permanecem estáveis. }\end{array}$ \\
\hline PAC & $\begin{array}{l}\text { - Os entrevistados mostram-se relutantes sobre o Programa de Aceleração do } \\
\text { Crescimento. Dizem não notar mudanças efetivas até o momento, não verem benefícios } \\
\text { para as moradias, não compreendem a real finalidade dos restauros e não veem impacto } \\
\text { do restauro nos eventos. }\end{array}$ \\
\hline Comentários & $\begin{array}{l}\text { - Há uma sugestão de melhoria da estrada de terra. } \\
\text { - Há reclamação da infraestrutura local para a população, falta de equipamento médico } \\
\text { para exame no Posto de Atendimento, farmácia, transporte. } \\
\text { - Faltam artistas com "nome de peso" para o Festival de Inverno. } \\
\text { - Apontam que "é um sacrifício" para o turista chegar até o local. }\end{array}$ \\
\hline
\end{tabular}

Fonte: Elaborado pelas autoras.

Apesar de os números de visitação turística na Vila de Paranapiacaba serem proeminentes, os moradores lidam com uma realidade ainda distante da prosperidade econômica. O rendimento médio por família é de $\mathrm{R} \$ 876,39$, um pouco mais do que o salário mínimo no Brasil em 2015 ( $\mathrm{R} \$ 788,00)$, embora $58 \%$ de sua população concentre-se na faixa etária entre 20 e 59 anos, idade economicamente ativa. Por isso, o salário associado ao turismo é uma realidade desejada. 
Quadro 2 - Síntese das Respostas de Entrevistas com órgão público de Santo André

\begin{tabular}{|c|c|c|}
\hline $\begin{array}{l}\text { Itens apontados } \\
\text { pela gestão } \\
\text { pública na } \\
\text { entrevista }\end{array}$ & $\begin{array}{l}\text { Apoio Administrativo de Paranapiacaba e } \\
\text { Parque Andreense - Gestão do Patrimônio } \\
\text { de Paranapiacaba }\end{array}$ & $\begin{array}{l}\text { Departamento de Turismo } \\
\text { Secretaria de Cultura de Turismo de } \\
\text { Santo André }\end{array}$ \\
\hline $\begin{array}{l}\text { Paranapiacaba e } \\
\text { Desenvolvimento }\end{array}$ & $\begin{array}{l}\text { - Características: neblina recorrente, baixas } \\
\text { temperaturas, alta umidade. } \\
\text { - Tombamentos do patrimônio tecnológico da } \\
\text { ferrovia e Mata Atlântica em seu entorno: } \\
\text { - 1987-Condephaat (Conselho de Defesa } \\
\text { do Patrimônio Histórico, Artístico, } \\
\text { Arqueológico e Turístico do Estado de São } \\
\text { Paulo); } \\
\text { - 2002-Iphan (Instituto do Patrimônio } \\
\text { Histórico e Artístico Nacional); } \\
\text { - 2003-Condephapaasa (Conselho Municipal } \\
\text { de Defesa do Patrimônio Histórico, Artístico, } \\
\text { Arquitetônico-Urbanístico e Paisagístico de } \\
\text { Santo André). } \\
\text { - Plano turístico: Criação do calendário } \\
\text { de eventos (Carnaval, Festa do Cambuci, } \\
\text { Festival de Inverno, Feira do Oratório). } \\
\text { - Melhoria de infraestrutura local. } \\
\text { - Restauros de imóveis. }\end{array}$ & $\begin{array}{l}\text { - Foi comprada por Santo André da } \\
\text { Rede Ferroviária Federal em } 2002 \\
\text { em virtude de sua falência. } \\
\text { - Houve incentivo para abertura de } \\
\text { empreendimentos. } \\
\text { - É atual candidata a patrimônio da } \\
\text { humanidade pela UNESCO. } \\
\text { - Importância histórica e cultural. } \\
\text { - Poucas mudanças na infraestrutura } \\
\text { urbana por conta do tombamento. } \\
\text { Construção de uma Escola de } \\
\text { Ensino Infantil, uma de Ensino } \\
\text { Fundamental e um posto de saúde. }\end{array}$ \\
\hline $\begin{array}{l}\text { Atividade } \\
\text { Turística e Perfil } \\
\text { do Turista }\end{array}$ & $\begin{array}{l}\text { - Fluxo anual: } 200 \text { mil visitantes. Aumento de } \\
31 \text { mil em } 2001 \text { para } 220 \text { mil em } 2008 . \\
\text { - Procedência dos visitantes: Região } \\
\text { Metropolitana de São Paulo. } \\
\text { - Classes: B e C. } \\
\text { - Familiar - entre } 25 \text { e } 40 \text { anos. } \\
\text { - Objetivo da administração: R } \$ 70,00 \text { de } \\
\text { ticket médio por pessoa. }\end{array}$ & $\begin{array}{l}\text { - Fomento ao contato com instituições } \\
\text { de ensino. } \\
\text { - Estudantes abordam a Vila direta e } \\
\text { indiretamente em suas pesquisas. } \\
\text { - Atrativos histórico-culturais. } \\
\text { - Atividades de ecoturismo. }\end{array}$ \\
\hline $\begin{array}{l}\text { Festival de } \\
\text { Inverno e } \\
\text { Dinâmica } \\
\text { Econômica }\end{array}$ & $\begin{array}{l}\text { - FIP é parte do plano de transformação em } \\
\text { polo turístico após aquisição pela Prefeitura } \\
\text { de Santo André em 2001. } \\
\text { - Ferramenta de promoção turística. } \\
\text { - } 70 \text { mil visitantes em dois finais de semana. } \\
\text { - Promoção da Vila através de projeção na } \\
\text { mídia. } \\
\text { - Impacto no fluxo turístico pré e pós-eventos } \\
\text { e fluxo anual. } \\
\text { - Parte de um conjunto de ações para mudar a } \\
\text { imagem externa da Vila, envolver moradores } \\
\text { no desenvolvimento econômico, criar } \\
\text { infraestrutura turística e identidade local. } \\
\text { - Moradores são empreendedores de } \\
\text { 90\% dos negócios da Vila. Cerca de } 80 \\
\text { empreendimentos totais locais. }\end{array}$ & $\begin{array}{l}\text { - Parte do plano anual de turismo. } \\
\text { - Chegou a atrair } 13 \text { mil pessoas por } \\
\text { dia. } \\
\text { - Foi pensado para reverter a má fama } \\
\text { da Vila nos anos de descaso. } \\
\text { - Não altera questões ambientais. } \\
\text { - Crescente número de visitantes } \\
\text { decorrentes do FIP levou a um } \\
\text { constante trabalho de estruturação } \\
\text { do turismo local. } \\
\text { - Aumento da renda dos moradores. } \\
\text { - Perfil ativo nas redes sociais para } \\
\text { promoção. }\end{array}$ \\
\hline
\end{tabular}




\begin{tabular}{|c|c|c|}
\hline Eventos na Vila & $\begin{array}{l}\text { - Ferramenta de ampliação e promoção do } \\
\text { turismo. }\end{array}$ & $\begin{array}{l}\text { - Comissão dos Festejos: comerciantes } \\
\text { participam do planejamento de } \\
\text { alguns eventos. } \\
\text { - Moradores organizam a } \\
\text { Festa do Padroeiro, a Feira de } \\
\text { Oratórios e atuam em conjunto } \\
\text { com administração pública na } \\
\text { organização do carnaval. } \\
\text { - Movimentam a vila culturalmente. } \\
\text { - A Vila é aberta a intervenções } \\
\text { artísticas e culturais. }\end{array}$ \\
\hline PAC & $\begin{array}{l}\text { - Adequação de imóveis para serviços } \\
\text { turísticos. } \\
\text { - Melhoria na qualidade do atendimento. } \\
\text { - Maior fluxo econômico. } \\
\text { - Projeção na mídia - Candidatura a } \\
\text { patrimônio da humanidade pela UNESCO. }\end{array}$ & $\begin{array}{l}\text { - Disponibilização de imóveis } \\
\text { abandonados. } \\
\text { - Mais publicidade. } \\
\text { - Revitalização de prédios históricos. } \\
\text { - Ampliação da capacidade de atividade } \\
\text { turística. }\end{array}$ \\
\hline
\end{tabular}

Fonte: Elaborado pelas autoras com dados das Entrevistas à Administração Geral de Paranapiacaba e à Secretaria de Cultural e Turismo de Santo André.

Dados refletem que, dos 960 moradores da Vila, 23\% estão ligados às atividades turísticas. Considerando o seu potencial, é um número ainda relativamente baixo. Tal fator pode ser relacionado com o fato de que $52 \%$ dos moradores não possuem instrução ou não completaram o Ensino Fundamental e apenas 3\% completou o Ensino Superior (PREFEITURA DE SANTO ANDRÉ, 2014a). A realidade, para Barreto (2002, p. 36), “[...] é que as pessoas de menor renda, geralmente com menos escolaridade, têm dificuldades para encontrar colocação no setor de turismo".

\section{Tabela 1 - Visitação Turística ${ }^{7}$}

\begin{tabular}{ccr} 
& Visitação Anual & \% cresc \\
\hline 2002 & 41.000 & 0 \\
2003 & 95.958 & 134,04 \\
2004 & 153.860 & 60,34 \\
2005 & 150.032 (até Julho)
\end{tabular}

7 PNMNP - Parque Natural Municipal Nascentes de Paranapiacaba.

Fonte: Moretto Neto (2005, p. 106). 
Tabela 2 - Visitação Turística

\begin{tabular}{l|r|r}
\hline Visitação & \multicolumn{1}{|c|}{2012} & \multicolumn{1}{|c}{2013} \\
\hline Visitação Geral (Vila de Paranapiacaba) & Não houve contagem & 268.234 \\
\hline Visitação do PNMNP & 17.698 visitantes & 19.346 visitantes \\
\hline Visitação do Centro de Visitantes & Não computada & 762 \\
\hline X Festival do Cambuci & n.d. & 9.472 \\
\hline XIII Festival de Inverno de Paranapiacaba & n.d. & 102.536 \\
\hline
\end{tabular}

Fonte: Secretaria de Gestão dos Recursos Naturais de Paranapiacaba e Parque Andreense apud Prefeitura de Santo André (2014b, p. 35).

No ano de 2013, a Vila sediou um total 16 eventos que gerou 210 postos de trabalho, dos quais 116.099 visitantes movimentaram financeiramente os empreendimentos em $\mathrm{R} \$$ 2.375.768 (PREFEITURA DE SANTO ANDRÉ, 2014a). Desses dados, há indícios na pesquisa de que o dinheiro gasto pelos visitantes e que, de fato, permanece na região de destinação turística para ser reciclado pela economia local ainda não é suficiente para estimular a dinâmica econômica da Vila de Paranapiacaba.

\section{Eventos como agente transformador nas comunidades}

Há um conflito entre os sentimentos dos moradores e os restauros do PAC em função da preservação histórica de Paranapiacaba, pois não compartilham da história que levou ao tombamento e sentem-se "presos" a regulamentação que essa condição impõe. Uma parcela significativa dos moradores não é natural da Vila e, possivelmente, por esse motivo, não compartilha de sua identidade histórica; por isso, acredita que outras prioridades devem ser levadas em consideração com um investimento de tamanho porte.

Sob essa ótica, entende-se que as atividades de turismo e de eventos podem construir a ponte entre passado e futuro, na qual os eventos que ali sejam realizados fortifiquem e ajudem no processo de compreensão e formação da identidade dos moradores, ao mesmo tempo, em que ofereçam a seus visitantes um intercâmbio entre passado e presente.

A participação em eventos, em qualquer esfera (público ou prestadorde serviço), enriquece avidacultural de seus agentes, 
pois é de sua natureza dirigir o olhar para um acontecimento específico em um período de tempo determinado e em uma localidade particular, o que potencializa a efetividade e o envolvimento de seus participantes. Ocasiona uma educação dos sentidos transmutados em novos conhecimentos e novas experiências (COUTINHO; COUTINHO, 2007).

Conforme Giglio e Carvalho (2013, p. 266-267) “[...] um documento que torna um local um patrimônio histórico não transforma as pessoas em atores da hospitalidade da noite para o dia nem atrai turistas". Para que o turismo fortifique suas bases comunitárias, é fundamental o treinamento e emponderamento dos moradores que atuam e representam uma parcela significativa e quase total dos empreendedores no setor turístico. A identidade do local precisa ser desenhada e assumida pelos moradores. Essa participação social é o que contribui para que o intercâmbio entre o público e a os receptores seja eficaz e a comunidade local não seja apenas reduzida a simples objeto de consumo.

Os eventos e sua demanda como um todo, se inseridos em uma política turística de base comunitária, representam uma potencialização da participação e envolvimento de seus agentes na tomada de decisões e nas diretrizes que melhor contribuem para a dinâmica individual de cada um, ainda que imersos em um conjunto de estratégias coletivas.

Para Granovetter (1985) apud Giglio e Carvalho (2013, p. 248) “[...] o [conceito] de imersão social: quanto mais comprometido e imerso na rede encontra-se um ator, maior é a sua segurança”. Ainda que, no início do desenvolvimento da atividade turística, houve uma série de atividades de qualificação profissional (MORETTO NETO, 2005), essas atividades precisam tornar-se uma prática constante e cogente para os comerciantes de Paranapiacaba.

Assim, a autonomia de gestão, o treinamento em atendimento ao consumidor e a gestão estratégica de marketing podem representar uma alteração no nível educacional e nas táticas empreendedoras da população de Paranapiacaba, representando mudanças no saldo econômico para a localidade 
e na renda dos moradores, especialmente àqueles ligados aos setores da atividade turística.

\section{Considerações finais}

O turismo cultural na Vila de Paranapiacaba estimulado pelo calendário de eventos tem representado uma recuperação econômica do local, conforme Moretto Neto e os dados da Prefeitura de Santo André esclarecem, requalificando a estrutura turística e identidade locais.

Nota-se que, embora muitos dos empreendimentos turísticos sejam geridos por moradores, a participação e envolvimento social bem como a representatividade do Conselho Municipal de Representantes de Paranapiacaba e Parque Andreense no desenho das políticas públicas de turismo e no planejamento de eventos precisam de maior destaque. A realidade atual de Paranapiacaba distancia-se dos tempos áureos do surgimento da Vila e sua economia ainda sofre com o descaso ao qual esteve suscetível no período entre o final da administração da São Paulo Railway e o início da administração de Santo André. A população que hoje habita a Vila sobrevive com baixa renda e falta de recursos básicos de saúde e educação. Acredita-se que os empreendimentos também possam potencializar-se com a injeção de recursos financeiros e com a superação dos percalços encontrados pelo tombamento do local. Para haver crescimento e consolidação econômica, são necessários o entendimento dos objetivos da comunidade, a priorização dos recursos e a avaliação das capacidades individuais.

Nesse sentido, com o contexto estudado, percebe-se que os eventos podem funcionar como ferramenta de aumento da renda da comunidade local e os planejadores de turismo podem utilizar-se de um trabalho de informação e conscientização dos moradores sobre a riqueza cultural da Vila, a fim de que possam apropriar-se de sua identidade e sentirem-se parte integrada de sua história e futuro desenvolvimento, conectando-se com o local. A Vila evoluiu rapidamente em 
15 anos, desde que se tornou polo turístico; contudo, ainda carece de infraestrutura que fomente a busca por experiência e o envolvimento emocional dos visitantes, aumentando seu tempo de permanência e seu ticket médio. A maior promoção de sua diversidade de eventos somada ao desenvolvimento do empreendedorismo local são fatores essenciais nas variáveis que contribuem para o desenvolvimento econômico local.

\section{Referências}

ALLIS, Thiago. Ferrovia e Turismo Cultural - Alternativa para o Futuro da Vila de Paranapiacaba (SP). Turismo em Análise, São Paulo, v. 13, n. 2, p. 29-53, 2002. Disponível em: <www.revistas.usp. br/rta/article/download/63597/66362> Acesso em: 15 set. 2015.

BARRETO, Margarita. Turismo e legado cultural: As possibilidades do planejamento.3.ed.Campinas: Papirus, 2002. (Coleção Turismo).

CANO, Wilson. Raízes da concentração industrial em São Paulo. 5. ed. Campinas: IE/UNICAMP, 2007.

Questão regional e urbanização no desenvolvimento econômico brasileiro pós 1930. Campinas: IE/UNICAMP, 1988.

CATRACA LIVRE. 10 ${ }^{\circ}$ Festival de Inverno de Paranapiacaba. 28 jun.2010. Disponível em: <https://catracalivre.com.br/geral/agenda/ barato/10\%C2\%BA-festival-de-inverno-de-paranapiacaba $>$. Acesso em: 10 nov. 2015.

COSTA, Fernando Nogueira da. Economia comportamental: de volta à filosofia, sociologia e psicologia. Texto para Discussão - IE/ UNICAMP, Campinas, n. 173, dez. 2009.

COUTINHO, Hevellyn Pérola Menezes; COUTINHO, Helen Rita Menezes. Turismo de Eventos como alternativa para o problema da sazonalidade turística. Revista Eletrônica Aboré Publicação da Escola Superior de Artes e Turismo, Amazonas, n. 3, p. 1-13, 2007. Disponível em: <http://www.revistas.uea.edu.br/old/abore/artigos/ artigos_3/Hevellyn\%20Perola\%20Menezes\%20Coutinho.pdf>. Acesso em: 8 nov. 2015.

CRUZ, Thaís Fátima dos Santos. Paranapiacaba: a arquitetura e o urbanismo de uma vila ferroviária. 2007. 219 f. Dissertação (Mestrado em Arquitetura e Uranismo) - Escola de Engenharia de São Carlos, São Carlos, 2007. Disponível em: <http://www.teses. 
usp.br/teses/disponiveis/18/18142/tde-10122007-090438/pt-br. php>. Acesso em: 16 out 2013.

DIRETORIA DE TURISMO DE PARANAPIACABA. Paranapiacaba - Trabalho de Graduação - Entrevista Informativa [mensagem pessoal]. Mensagem recebida por <turismoparanapiacaba@santoandre.sp.gov.br> em 23 nov. 2015.

GIGLIO, Ernesto Michelangelo; CARVALHO, Marcius Fabius. As Transformações das Redes de Negócios na Perspectiva da Teoria Social: o caso da Vila de Paranapiacaba - SP. 2013. Turismo em Análise, São Paulo, v. 24, n. 2, p. 248-277, 2013. Disponível em: <http://www.publicacoesdeturismo.com.br/ref.php?id=4675>. Acesso em: 8 nov. 2015;

GUTIERRE, Gislaine. Paranapiacaba já prepara o Festival de Inverno. Diário do Grande ABC. 15 fev. 2002. Disponível em: <http://www.dgabc.com.br/Noticia/296211/paranapiacaba-japrepara-o-festival-de-inverno-2002 >. Acesso em: 12 nov. 2015.

IGNARRA, Luiz Renato. Dinâmica dos eventos turísticos e seu impacto na hotelaria paulistana. 2007. 253 f. Tese (Doutorado em ciências da Comunicação). Departamento de Relações Públicas, Propaganda e Turismo. Universidade de São Paulo, São Paulo, 2007. Disponível em: <www.teses.usp.br/teses/disponiveis/27/27148/tde22072009.../1174052.pdf>. Acesso em: 8 nov. 2015.

JORNAL DA ORLA. Festival de Inverno de Paranapiacaba. Turismo. 19 jul. 2009. Disponível em: <http://www.jornaldaorla. com.br/noticias/7681-festival-de-inverno-de-paranapiacaba/>. Acesso em: 12 nov. 2015.

LAGE, Beatriz Helena Gelas; MILONE, Paulo César. Impactos socioeconômicos do Turismo. 1998. Revista de Administração, São Paulo, v. 33, n. 4, p. 30-44, out./dez. 1998. Disponível em: $<$ http://200.232.30.99/download.asp?file=3304030.pdf $>$. Acesso em: 8 nov. 2015.

MATIAS, Marlene (Org.). Planejamento, organização e sustentabilidade em eventos culturais, sociais e esportivos. Barueri: Manole, 2011.

MINISTÉRIO DO TURISMO. Instituto Brasileiro de Administração Municipal. Classes $\mathrm{C}$ e D, um novo mercado para o turismo brasileiro. Relatório Final. Análise de Dados de Pesquisa Quantitativa e Qualitativa. Brasília: Ministério do Turismo, [s. d].

. Secretaria Nacional de Políticas de Turismo. Departamento de Estruturação, Articulação e Ordenamento Turístico. Coordenação 
Geral de Segmentação. Segmentação do turismo e o mercado.

Brasília: Ministério do Turismo, 2010. Disponível em: <http://www. turismo.gov.br/sites/default/turismo/o_ministerio/publicacoes/ downloads_publicacoes/Segmentaxo_do_Mercado_Versxo_Final_ IMPRESSxO_.pdf>. Acesso em: 30 out. 2015.

MORETTO NETO, Marco. Protagonismo comunitário em Paranapiacaba: o impacto das ações governamentais no desenvolvimento sócio econômico-comunitário da vila de Paranapiacaba no período de 2001 a 2004. 2005. 181 f. Dissertação (Mestrado em Administração) - Programa de Pós- Graduação em Administração, Universidade Municipal de São Caetano do Sul, São Caetano do Sul, 2005. Disponível em: <http://www.uscs.edu.br/ posstricto/administracao/dissertacoes/2005/marco_moretto_neto/ protagonismo_comunitario_em_paranapiacaba.pdf $>$. Acesso em: 3 nov. 2013.

NEVES, Cássio Gomes. Paranapiacaba ganha Festival de Inverno. Diário do Grande ABC. 25 jun. 2001. Disponível em: <http://www.dgabc.com.br/(X(1)S(irxvtx1rrlmcekko0wzp0g51))/ Noticia/277436/paranapiacaba-ganha-festival-de-inverno >. Acesso em: 12 nov. 2015 .

Festival de Paranapiacaba tem sol e milhares de pessoas. Diário do Grande ABC. 24 jul. 2006. Disponível em: <https:// www.dgabc.com.br/(X(1)S(0xotwybbzqn1tuvrpvpytd2u))/ Noticia/440880/festival-de-paranapiacaba-tem-sol-e-milhares-depessoas>. Acesso em: 12 nov. 2015.

OLIVEIRA, Mariana. Festival de Paranapiacaba agita a economia local. Diário do Grande ABC. Economia. 16 jul. 2005. Disponível em: <http://www.dgabc.com.br/Noticia/258725/festival-deparanapiacaba-agita-a-economia-local>. Acesso em: 12 nov. 2015.

PAIVA, Fabiana Silva. O Processo de decisão sob a perspectiva da economia comportamental e da neurociência. 2013. 104 f. Dissertação (Mestrado em controlo e estão de Negócios) - Instituto Superior de Contabilidade e Administração de Lisboa, Instituto Politécnico de Lisboa, Lisboa, 2013. Disponível em: $\quad<$ http://repositorio.ipl.pt/bitstream/10400.21/2421/1/ Disserta\%C3\%A7\%C3\%A3o_Fabiana\%20Paiva_VFinal.pdf >. Acesso em: 3 nov. 2015.

PREFEITURA DE SANTO ANDRÉ. Paranapiacaba. 2013. Disponível em: <http://www2.santoandre.sp.gov.br/index.php/ paranapiacaba $>$. Acesso em: 11 set. 2015. 
. Anuário de Santo André. 2014a. Disponível em: <http:// www2.santoandre.sp.gov.br/index.php/2014-09-10-19-59-37/ publicacoes/category/3-anuarios-de-santo-andre>. Acesso em: 10 nov. 2015.

. 2014b. Disponível em <http://www2.santoandre. sp.gov.br/index.php/2014-09-10-19-59-37/publicacoes/ category/3-anuarios-de-santo-andre>. Acesso em: 10 nov. 2015.

2016. Disponível em <http://www2.santoandre. sp.gov.br/index.php/component/phocadownload/file/684-anobase-2015>. Acesso em: 06 jun.2017

15 Festival de Inverno de Paranapiacaba começa neste sábado (18). 2015. Disponível em: <http://www2.santoandre.sp.gov. br/index.php/festival-de-inverno>. Acesso em: 18 set. 2015.

ROSATI, César. Paranapiacaba ganha mil verba recorde de $\mathrm{R} \$ 42,4$ mi para revitalização. Folha Online. 7 set. 2013. Disponível em: <http://www1.folha.uol.com.br/cotidiano/2013/09/1338434paranapiacaba-sp-ganha-verba-recorde-de-r-424-mi-pararevitalizacao.shtml>. Acesso em: 2 set. 2015.

SOARES, Alessandro. Paranapiacaba prepara seu $3^{\circ}$ Festival. Diário do Grande ABC. 19 abr. 2003. Disponível em: < http://www. dgabc.com.br/(X(1)S(etehljvjgr3cedqzvssfo1oj))/Noticia/225667/ paranapiacaba-prepara-seu-3-festival-de-inverno >. Acesso em: 12 nov. 2015.

SOUZA JÚNIOR, Jalmir Pinheiro de. Viajando pela Experiência do FIG - Festival de Inverno de Garanhuns: um estudo sob a Perspectiva da Fenomenologia de Maurice Merleau-Ponty. 2013. 158 f. Dissertação (Mestrado em Administração) - Programa de Pós-Graduação em Administração, Universidade Federal de Pernambuco, Recife, 2013. Disponível em: <www.repositorio.ufpe. br/handle/123456789/10937>. Acesso em: 18 out. 2015.

STIGLIANO, Beatriz Veroneze; CESAR, Pedro de Alcântara Bittencourt. Vila Ferroviária de Paranapiacaba: o uso turístico do patrimônio. In: SEMINÁRIO DE PESQUISA EM TURISMO DO MERCOSUL (SEMINTUR) TURISMO: INOVAÇÕES DA PESQUISA NA AMÉRICA LATINA, 5., 27-28 jun. 2008. Caixas do sul. Anais... Caixas do sul: Universidade de Caxias do Sul, 2008. p. 1-10. Disponível em: <http://www.santoandre.sp.gov.br/ biblioteca/bv/hemdig_txt/131021002e.pdf>. Acesso: em 2 ago. 2015.

XU, Jing Bill. Perceptions of tourism products. Tourism Management, v. 31, p. 607-610, oct. 2009. 
VIEIRA, Pedro Cosme da Costa. Introdução à teoria do consumidor. 2004. Faculdade de Economia do Porto. Disponível em: <http:// www.fep.up.pt/docentes/pcosme/trabalhos/22-microeconomia. pdf>. Acesso em: 8 nov. 2015.

Submetido em: 22/08/2016

Aceito em: 07/06/2017

\title{
PARANAPIACABA: DYNAMIC ECONOMIC IN FUNCTION OF ITS EVENTS
}

\begin{abstract}
The village of Paranapiacaba holds a historical and cultural patrimony from São Paulo State occupation during coffee's economy development. Since its acquisition by Santo André City in 2001, a series of strategies, like Paranapiacaba Winter's Festival and an extensive Events Calendar, has been planned in order to increase tourism and recover the economy of that region. Listed as local, state and federal cultural heritage, the village is candidate for World Heritage by UNESCO. Since 2013 it has received an investment of 42 million Brazilian Reais $(\mathrm{R} \$)$ from Growth Acceleration Program for its restauration, which can turn it into one of the biggest touristic spots of São Paulo State. Given this scenario, this research presents bibliographic review, Santo Andre City's data, interviews with the public agency and formulary answered by local businesspeople to understand tourism enhancement in the region through its events and economic diversity arising from them. It was noticed the need of building a local identity from which residents can feel part of the city's patrimony. Therefore, Paranapiacaba's economic consolidation needs to raise from an interrelation between community and the public agency in order to have its resources prioritized and its entrepreneurship capability developed. Diversification in its events calendar shows a potential for community transformation generating results that enhance its subjects' individuality.
\end{abstract}

Keywords: Paranapiacaba. Events. Cultural Tourism. Economic Dynamics. 